\title{
Revista Brasileira de Enfermagem REBEn \\ Intervenções de enfermagem nas complicações mais freqüentes durante a sessão de hemodiálise: revisão da literatura
}

REVISÃo

\author{
Nursing interventions for the most frequent complications during hemodialysis \\ procedure: literature review \\ Intervenciones de enfermería en las complicaciones más frecuentes durante la \\ sesión de hemodialisis: revisión de la literatura
}

\section{Cristiano Dias Nascimento}

Estudante do $4^{\circ}$. ano da Faculdade de Enfermagem da Universidade de Santo Amaro. nasciimento@hotmail.com

Isaac R. Marques

Enfermeiro. Mestre em Enfermagem. Professor Adjunto da Faculdade de Enfermagem da Universidade de Santo Amaro. Orientador do

Trabalho.

isaacrm@terra.com.br

Trabalho de Conclusão de Curso apresentado à Faculdade de Enfermagem da Universidade de Santo Amaro.

\section{RESUMO}

O procedimento hemodialítico tem complicações potenciais e o enfermeiro deve estar apto a intervir em tais complicações. Considerando este contexto, este artigo tem como objetivo descrever as complicações mais freqüentes relacionadas à hemodiálise e as intervenções de enfermagem a elas relacionadas. Esta revisão de literatura consiste em pesquisa as Bases de Dados, LILACS, BEDENF E MEDLINE, utilizando descritores pertinentes. Os resultados demonstraram que as complicações que ocorrem com maior freqüência são: hipotensão, hipertensão, cãibras musculares, náusea e vômito, cefaléia, dor torácica e lombar, prurido, febre e calafrios. Concluiu-se que o papel do enfermeiro é essencial para a monitorização, detecção e intervenção em tais complicações e que este é um diferencial para a obtenção de segurança e qualidade no procedimento hemodialítico. No entanto, existe a necessidade de realização de mais pesquisas na área de enfermagem para melhor definir a atuação do enfermeiro.

Descritores: Insuficiência Renal Cônica/terapia; Hemodiálise/complicações; Cuidados de enfermagem.

\section{ABSTRACT}

Hemodialysis procedure has potential complications and nurses must be able to intervent on them. Considering this context, this article aims to describe the most frequent hemodialysis-related complications as well as nursingrelated interventions. This bibliographic review consists in LILACS, BDENF and MEDLINE search using pertinent descriptors. Results demonstrated that major complications are: hypotension, hypertension, cramps, nausea and vomiting, headache, chest and low back pain, scratching, fever and shriving. For these complications there are specific nursing interventions that can be delivered. It was concluded that nurse's role is essential for monitoring, identification, and intervention in such complications and that this role also is a differential to obtain quality in hemodialysis procedure. However, there is a need to perform more research in nursing area to better define the nurse's role.

Descriptors: Kidney Failure, chronic/therapy; Hemodialysis/complications; Nursing care.

\section{RESUMEN}

Lo procedimiento de hemodialisis tiene complicaciones potenciales y los enfermeros deben estar aptos a intervenir en ellos. Al considerar esto contexto, lo artículo objectiva describir las complicaciones más frecuentes relacionadas a la hemodialisis así como las intervenciones de enfermería. Esta revisión bibliografica ha consistido de busqueda a las basis de datos LILACS, DBENF y MEDLINE usandose descriptores pertinentes. Resultados han demonstrado que las mayores complicaciones son: hipotensión, hipertensión, distres musculares, nausea, vomitos, cefalea, dolor toracica y lumbar, prurido, fiebre y calafrios. Se ha concluido que el papel del enfermero es esencial para la monitorización, identificación y intervención en estas complicaciones y que esto papel tanbien es uno diferencial para obterse la calidad en lo procedimiento hemodialitico. Entremientes, hay una necessidad de realizarse más pesquisas en la area de enfermería para mejor definirse el papel de lo enfermero. Descriptores: Insuficiencia Renal Crónica/terapia; Hemodiálisis/complicaciones; Atención de enfermería

Nascimento CD, Marques IR. Intervenções de enfermagem nas complicações mais freqüentes durante a sessão de hemodiálise: revisão da literatura. Rev Bras Enferm 2005 nov-dez; 58(6):719-22.

\section{INTRODUÇÃO}

A Insuficiência Renal Crônica (IRC) refere-se à perda progressiva e irreversível da função renal. Se não houver tratamento, levará o paciente a morte. A IRC pode ser tratada por meio da hemodiálise em pacientes selecionados, cujo principal critério é ter uma função cardíaca estável(1-4).

A hemodiálise é o processo de filtragem e depuração do sangue de substâncias indesejáveis como a creatinina e a uréia que necessitam ser eliminadas da corrente sangüínea humana devido à deficiência no mecanismo de filtragem nos pacientes portadores de IRC. Na hemodiálise, a transferência de solutos ocorre entre 0 sangue e a solução de diálise através de uma membrana 
semi-permeável artificial (filtro de hemodiálise ou capilar) por três mecanismos: a difusão, que é o fluxo de soluto de acordo com o gradiente de concentração, sendo transferida massa de um local de maior concentração para um de menor concentração, isso depende do peso molecular e características da membrana. A ultrafiltração é a remoção de líquidos através de um gradiente de pressão hidrostática e a convecção é a perda de solutos durante a ultrafiltração, quando ocorre 0 arraste de solutos na mesma direção do fluxo de líquidos através da membrana ${ }^{(1-4)}$.

Atualmente, obtem-se um grande progresso em relação à segurança e a eficácia das máquinas de hemodiálise, tornando o tratamento mais seguro. Existem alarmes que indicam qualquer alteração que ocorra no sistema (detectores de bolhas, alteração de temperatura e do fluxo do sangue entre outros), mesmo assim, isso não garante que as complicações deixem de ocorrer ${ }^{(1,3)}$.

As complicações que ocorrem durante a sessão de hemodiálise podem ser eventuais, mas algumas são extremamente graves e fatais. A equipe de enfermagem tem importância muito grande na observação contínua dos pacientes durante a sessão, podendo ajudar a salvar muitas vidas e evitar muitas complicações ao fazer o diagnóstico precoce de tais intercorrências. 0 paciente deve ter extrema confiança nos profissionais prestativos, atenciosos e que estão sempre alerta para intervir quando necessário(3)

O entendimento do que vem ser uma diálise adequada vem sofrendo mudanças ao longo dos anos. Se nos primórdios da diálise poderia ser razoável ter como objetivo evitar a morte por hipovolemia ou hipervolemia, hoje o tratamento dialítico busca a reversão dos sintomas urêmicos e, a diminuição do risco de mortalidade, a melhoria da qualidade de vida e a reintegração social do paciente ${ }^{(2)}$.

A partir de observações empíricas, os autores do presente trabalho pontuam que a enfermagem é o grupo profissional que mais participa diretamente no processo de que envolve a hemodiálise, incluindo a atuação na resolução de possíveis complicações.

Como citam os autores ${ }^{(1-5)}$, a freqüência das complicações é grande. Atualmente a hemodiálise busca a reversão não somente dos sintomas urêmicos, mas também a redução das complicações que são inerentes ao próprio procedimento e a diminuição do risco de mortalidade. Por este motivo os profissionais de enfermagem devem estar sempre atualizados para promover um tratamento com segurança e qualidade ao paciente renal crônico.

Diante deste contexto, este trabalho tem como objetivo identificar, a partir de revisão da literatura científica, as complicações mais freqüentes durante a hemodiálise, correlacionando-as com as intervenções de enfermagem

\section{METODOLOGIA}

Trata-se de um estudo de revisão de literatura considerando os materiais disponíveis nas bases de dados bibliográficos LILACS, BDENF e MEDLINE. A expressão de pesquisa constou dos seguintes unitermos: "hemodiálise", "complicações" e "tratamento" (em inglês "hemodialysis", "complications" e "treatment"). Os seguintes limites foram estipulados: período compreendido entre 1993 e 2004, idioma português e inglês.

Do resultado do proceso de pesquisa junto às bases de dados e no acervo da biblioteca, foram selecionadas 107 publicações, das quais 38 estavam relacionadas diretamente com as complicações durante a hemodiálise. Destes, somente 24 foram recuperados e empregados na elaboração deste estudo. Demais materiais utilizados foram obtidos a partir de pesquisa não-sistemática em bibliotecas locais, considerandose a sua pertinência e a relevância de sua citação em trabalhos consultados.

Para análise e síntese do material observaram-se os seguintes procedimentos: a) leitura informativa ou exploratória, que constituiu na leitura do material para saber do que tratavam os artigos; b) leitura seletiva, que se preocupou com a descrição e seleção do material quanto à sua relevância para 0 estudo, excluindo-se os artigos que não eram pertinentes ao tema de interesse; c) leitura crítica ou reflexiva que buscou as definições conceituais sobre complicações durante a hemodiálise, aspectos fisiopatológicos, etiologia, sinais e sintomas, alternativas terapêuticas e as intervenções de enfermagem. Quanto às intervenções de enfermagem específicas para cada complicação, foram consideradas aquelas que são preventivas e terapêuticas.

\section{RESULTADOS E DISCUSSÃO}

\section{Complicações durante a sessão de hemodiálise e a atuação da enfermagem}

As complicações mais comuns durante a hemodiálise são, em ordem decrescente de freqüência, hipotensão (20\%-30\% das diálises), cãibras (5\%-20\%), náuseas e vômitos (5\%-15\%), cefaléia (5\%), dor torácica (2\%-5\%), dor lombar (2\%-5\%), prurido (5\%), febre e calafrios (<1\%). As complicações menos comuns, mas sérias e que podem levar à morte incluem: a síndrome do desequilíbrio, reações de hipersensibilidade, arritmia, hemorragia intracraniana, convulsões, hemólise e embolia $\operatorname{gasosa}^{(1,3,6-10)}$.

\section{Hipotensão}

A hipotensão é a complicação mais freqüente durante a hemodiálise, sendo um reflexo primário da grande quantidade de líquidos que é removida do volume plasmático durante uma sessão rotineira de diálise. A água acumulada no intervalo interdialítico é retirada diretamente pelo mecanismo de ultrafiltração $0^{(1-3)}$.

Quando o ritmo de ultrafiltração ultrapassar a capacidade de reenchimento vascular, ocorrerão hipovolemia e hipotensão arterial. Em geral, as causas comuns da hipotensão durante a hemodiálise são: flutuações na velocidade de ultrafiltração, velocidade de ultrafiltração alta, peso seco almejado muito baixo, medicamentos anti-hipertensivos, superaquecimento da solução de diálise, ingestão de alimentos, neuropatia autônoma, isquemia tecidual, disfunção diastólica, freqüência cardíaca e contratilidade. Os sintomas variam de tontura e sensação de desfalecimento, náuseas, calor e sudorese, dificuldades respiratórias e cãibras musculares, bocejos freqüentes, dor precordial, palidez cutânea, apatia, confusão mental e taquicardia ${ }^{(1-5,11-16)}$.

A intervenção consiste em iniciar imediatamente o tratamento de episódios agudos de hipotensão. 0 paciente deve ser colocado em posição de Trendelemburg, deve ser administrados bolus de $100 \mathrm{ml}$ de SF a $0,9 \%$ ou mais se necessário, a velocidade de ultrafiltração deve ser reduzida para o mais próximo possível de zero ${ }^{(1,3,4)}$.

Intervenções de enfermagem como o monitoramento cuidadoso dos sinais vitais e observação de sintomas específicos podem ajudar a limitar a ocorrência e a intensividade de episódios hipotensivos nesses pacientes ${ }^{(3,4)}$.

\section{Cãibras musculares}

As cãibras musculares durante a hemodiálise acontecem quando os líquidos e eletrólitos deixam rapidamente o espaço extracelular. Os fatores predisponentes mais importantes são: hipovolemia e hipotensão. Geralmente as cãibras ocorrem juntamente com a hipotensão, embora possam persistir após o restabelecimento da pressão arterial. No paciente abaixo do peso seco, as cãibras intensas e persistentes podem ocorrer quando o mesmo é desidratado até níveis inferiores ao seu peso seco. $\mathrm{O}$ uso de solução dialítica pobre em sódio também tem sido associada a uma alta incidência de cãibras musculares ${ }^{(1-4,6,8,17)}$.

Como geralmente as cãibras musculares ocorrem concomitantemente com a hipotensão, a administração de solução de glicose ou soro fisiológico hipertônico é muito eficaz no tratamento agudo das cãibras musculares, podendo também ser utilizado gluconato de cálcio. 
Essas soluções também agem transferindo água osmoticamente em direção ao compartimento sangüíneo, auxiliando a manter o volume sangüíneo. A administração de glicose hipertônica é preferida para 0 tratamento de cãibras em pacientes não-diabéticos ${ }^{(1,3,4,6)}$.

A prevenção dos episódios hipotensivos eliminaria a maior parte dos episódios de cãibras. A elevação do nível de sódio do banho da diálise também pode ajudar a evitar os episódios de cãibras musculares durante e após o tratamento $0^{(1,3,4,4,8)}$.

\section{Náuseas e vômitos}

Náuseas e vômitos são ocorrências comuns e ocorrem em até 10\% dos tratamentos rotineiros de diálise, sendo sua etiologia multifatorial. A maioria dos episódios em pacientes estáveis provavelmente esteja relacionada à hipotensão, mas também podem ser uma manifestação precoce da síndrome do desequilíbrio ${ }^{(1-4,8)}$.

Deve-se tratar primeiramente a hipotensão, caso presente. Caso as náuseas e vômitos persistirem pode-se administrar um antiemético. É de extrema importância evitar a hipotensão durante a diálise. Em alguns pacientes, a redução da velocidade de fluxo sangüíneo em $30 \%$ durante a primeira hora de diálise pode ser benéfica. No entanto, o tempo de tratamento deve ser prolongado proporcionalmente ${ }^{(1,3,4,8)}$.

\section{Cefaléia}

A causa da cefaléia é em grande parte desconhecida, podendo ser uma manifestação da síndrome do desequilíbrio ou relacionada à hipertensão arterial, assim como pode também estar relacionada à manifestação da abstinência de cafeína em pacientes que ingerem muito café, pois a diálise retira essa substância. Em geral a diálise pode induzir a cefaléia severa em conseqüência de uma quantidade grande de deslocamento da água e do eletrólito ${ }^{(1-4,7,8,18-20)}$.

O tratamento é realizado com o uso de analgésicos por via oral ou parenteral. Como para náuseas e vômitos, uma redução na velocidade de fluxo sanguíneo durante a parte inicial da diálise pode ser tenta$\mathrm{da}^{(1,3,7,8)}$.

\section{Dor torácica e dor lombar}

A dor torácica está frequentemente associada à dor lombar ocorrendo em 1-4\% dos tratamentos de diálise. A causa é desconhecida, mas pode estar relacionada à ativação do complemento (uma função que envolve a estutura da Imunoglobulina e que ativa as respostas humorais). Não existe tratamento específico nem estratégia de prevenção, a não ser a troca para uma membrana sintética ou de celulose substituída (o fato de tal alteração ajudar ou não ainda é motivo de controvérsias). A ocorrência de angina durante a diálise é comum, e esta, assim como as numerosas outras causas potenciais de dor torácica, por exemplo, a hemólise, que deve ser considerada no diagnóstico diferencial(1,3). No caso da angina, existe relação direta com a redução da volemia que leva ao baixo débito cardíaco momentâneo. 0 mecanismo imediato de resposta é o aumento da secreção de epinefrina que induz a vasoconstrição coronariana.

\section{Prurido}

O prurido (coceira) é o sintoma de pele mais importante nos pacientes urêmicos. Em uma pesquisa, $80 \%$ dos pacientes submetidos à hemodiálise de manutenção apresentaram coceira em algum momento(3). No geral, o prurido foi frequentemente mais grave durante ou após uma sessão de hemodiálise ${ }^{(1,3)}$.

O prurido, além de ser uma complicação durante a sessão de hoemodiálise, também é a manifestação mais comum nos portadores de IRC, e tem sido atribuído ao efeito tóxico da uremia na pele. As toxinas urêmicas circulantes são responsáveis pelo prurido, que pode desaparecer como o inicio do tratamento de hemodiálise; contudo, a terapia nem sempre alivia, podendo, inclusive, piorá-lo. Um produto cálcio-fósforo elevado pode contribuir para o processo. O prurido pode também estar associado à alergia a heparina e resíduos de óxido de etileno, por exemplo. Em alguns pacientes a sensação é tão intensa que causa escoriações na pele, crostas hemorrágicas, pústulas e formação de nódulos. Essas lesões ocorrem na face, nas costas, no tronco e nas extremidades ${ }^{(1,3)}$.

Um grande número de tratamentos está em voga. Alguns tratamentos são eficazes como emolientes tópicos à base de cânfora, aplicação de ultravioleta, uso de carbonato de cálcio, quando o produto cálcio-fósforo for elevado e dieta para controle do fósforo, o uso de anti-histamínicos por via oral ou endovenosa e a paratireoidectomia está indicada para os pacientes com osteodistrofia e hiperparatireoidismo grave ${ }^{(1,3)}$.

\section{Febre e calafrios}

O paciente renal crônico é imunodeprimido e, consequentemente, tem uma suscetibilidade aumentada para infecções. As infecções bacterianas nos pacientes renais crônicos parecem progredir de maneira rápida e a cura parece ser mais lenta. O loca de acesso é a fonte de $50 \%$ a $80 \%$ das bacteremias (principalmente pacientes com cateteres). As bacteremias podem causar endocardite, meningite e osteo-mielite $e^{(1,3,4,17,21-23)}$.

Febre de baixa intensidade durante a hemodiálise pode estar relacionada a pirogênios presentes na solução dialítica e não a uma infecção verdadeira. O tempo de evolução da febre pode ser útil para a distinção entre reação pirogênica e infecção. Os pacientes com febre relacionada ao pirogênio são afebris antes da diálise, mas tornam-se febris durante a diálise; a febre desaparece espontaneamente após o término da diálise. Os pacientes com septicemia relacionada ao local de acesso frequentemente são febris antes da instituição da diálise, e, na ausência do tratamento, a febre persiste durante e após a diálise ${ }^{(1,3,4,17,21,22)}$.

Nos pacientes que apresentam picos febris durante a hemodiálise deve-se verificar a temperatura do paciente e da máquina de hemodiálise, colher amostras de cultura, o uso de medicamentos como antitérmicos e antibióticos a critério médico e colher cultura da água para hemodiálise ${ }^{(1,3,4)}$.

No caso de um tratamento de uma presumível infecção do acesso vascular em um paciente de diálise febril com cateter temporário (subclávio, jugular interno ou femoral), caso não exista fonte óbvia de infecção, devem ser realizadas culturas sangüíneas e também a remoção do cateter. $O$ atraso na remoção de um cateter infectado pode resultar em complicações sépticas que poderiam ser evitadas ${ }^{(1,3,4,21,22)}$.

\section{Hipertensão}

A hipertensão durante a diálise é geralmente produzida por ansiedade, excesso de sódio e sobrecarga de líquidos. Isso pode ser confirmado comparando-se o peso do paciente antes da diálise com 0 peso ideal ou seco. Quando a sobrecarga hídrica é a causa da hipertensão, a ultrafiltração trará, geralmente, uma redução na pressão sanguínea, levando à normalização da pressão(1-9,14,24).

O temor, a ansiedade e a apreensão, podem produzir hipertensão passageira e errática. Após a administração de anti-hipertensivo, a enfermagem monitora a pressão arterial em intervalos freqüentes (geralmente de 15 em 15 minutos). Os sedativos podem ser necessários, mas a confiança na equipe e uma diálise suave, livre de problemas, ajudarão a reduzir a ansiedade durante ao tratamentos subseqüentes ${ }^{(1-9,14,24)}$.

\section{CONCLUSÕES}

A principal complicação que ocorre durante a hemodiálise envolve as alterações hemodinâmicas decorrentes do processo de circulação extracorpórea e a remoção de um grande volume de líquidos em um espaço de tempo muito curto. A atuação do enfermeiro diante desta complicação, desde a monitorização do paciente, a detecção de anormalidades e a rápida intervenção é essencial para a garantia de um procedimento seguro e eficiente para o paciente. Como o enfermeiro 
é o profissional que assiste mais de perto o paciente nas sessões de hemodiálise, ele deve estar apto a prontamente intervir e assim evitar outras potenciais complicações.

Na maioria dos trabalhos consultados, percebeu-se a necessidade de discutir 0 assunto das complicações durante a hemodiálise. Das publicações nacionais, a maioria enfoca este problema. Destas publicações, poucas são oriundas de publicações de enfermagem e/ou escritas por enfermeiros, algo que pode estar relacionado ao pouco número de pesquisas realizadas pela enfermagem nesta área. Outro aspecto observado nos trabalhos citados, tendo como origem publicações de enfermeiros, é que estes trabalhos não são atuais e que

\section{REFERÊNCIAS}

1. Dalgirdas JT. Manual de diálise. $3^{\mathrm{a}}$. Ed. Rio de Janeiro (RJ): Medsi; 2003.

2. Riella MC. Princípios de nefrologia e distúrbios hidroeletrolíticos. $4^{\mathrm{a}}$. ed. Rio de Janeiro (RJ): Guanabara Koogan; 2003.

3. Fermi MRV. Manual de diálise para enfermagem. Rio de Janeiro (RJ): Medsi; 2003.

4. Barros E, Manfro RC, Thomé FS, Gonçalves LFS. Nefrologia, rotinas, diagnóstico e tratamento. 2a . ed. Porto Alegre (RS): Artmed; 1999.

5. Hudak CM, Gallo BM. Cuidados intensivos de enfermagem. $6^{\mathrm{a}}$ ed. Rio de Janeiro (RJ): Guanabara Koogan; 1994.

6. Calixto RC, Lorençon M, Corrêa MSMF, Cruz AP, Martins LC, Barretti $P$, et al. Intercorrências dialíticas em hemodiálise. J Bras Nefro 2003 25 (Supl 1): 7 HD ENF 16.

7. Reis EMK, Silva TD, Garcia TSE. Eventos mórbidos intradialíticos: tipos e frequêencia em relação ao dialisato com e sem glicose a 1\%. J Bras Nefro 2003; 25 (Supl 1): 7; HD ENF 17.

8. Reis EMK, Silva TS. Eventos mórbidos intradialíticos em nefropatas diabétidos e não diabéticos: caracterização e condutas. J Bras Nefro 2003; 25 (Supl 1): 7; HD ENF 18.

9. Dias TS, Reis EMK. Eventos mórbidos em sessões de hemodialíticas: otmização das ações de enfermagem. J Bras Nefro 2003; 25 (Supl 1): 9; HD ENF 24.

10. Rodrigues MCS. A atuação do enfermeiro no cuidado ao portador de insuficiência renal crônica no contexto biotecnológico da hemodiálise. Nursing 2005; 82 (8): 135-42.

11. Dheenan S, Venkatesan J, Grubb BP, Henrich WL. Effect of sertraline hydrochloride on dialysis hypotension. Am J Kdney Dis 1998; 31(4) 624-30.

12. Kes P. Acute hypotention and shock in the hyperkalemic patient on maintenance haemodialysis. Nephron 1996; 72: 484-6.

13. Donauer J. Hemodialysis-induced hypotension: impact of technologic advances. Sem Dialysis 2004; 17(5): 333-5. não utilizam um padrão de linguagem ou terminologia de enfermagem tanto para a elaboração de diagnósticos como para intervenções de enfermagem. Nestas publicações, o modelo biomédico para denominar problemas/ complicações e como resolvê-los, é fortemente percebido como influência para o fazer do enfermeiro.

Diante do que foi exposto neste trabalho, percebe-se que existe a necessidade de realização de pesquisas sobre as complicações que ocorrem durante a hemodiálise. Um potencial benefício será obtido com a finalidade de identificar um padrão/perfil de diagnósticos de enfermagem para tais complicações, assim como também para definir quais sejam as intervenções específicas de acordo com uma terminologia padronizada de enfermagem.

14. Ligtenberg G. Regulation of blood pressure in chronic renal failure: determinants of hypertension and dialysis-related hypotension. Netherlands J Med 1999; 55: 13-8.

15. Yalcin AU, Kudaiberdieva G, Sahin G. Effect of sertraline hydrochloride on cardiac autonomic dysfunction in patients with hemodialysisinduced hypotension. Nephron Physiol 2003; 93: 21-8.

16. Kianfar C, Rothera C, Lindsay RM. On-line optical sensing of blood volume changes to prevent intradialytic hypovolemia. Can J 1999; 9(4): 29-32, quiz 33-4, 35-40.

17. Chang CT, Wu CH, Yang CW, Huang JY, Wu MS. Creatine monohydrate treatment alleviates muscle cramps associated with haemodialysis. Nephrol Dial Transplant 2002; 17(11): 1978-81.

18. Antoniazzi AL, Bigal ME, Bordini CA, Speciali JG. Headache and hemodialysis: a prospective study. Headache 2003; 43(2): 99-102.

19. Antoniazzi AL, Bigal ME, Bordini CA, Speciali JG. Headache associated with dialysis: the international headache society criteria revisited. Cephalalgia 2003; 23(2): 146-149.

20. Goksan B, Karaali-Savrun F, Ertan S, Savrun M. Haemodialysisrelated headache. Cephalalgia 2004; 24(4): 284-7.

21. Pereira FD, Ferreira V, Lousada RAP, Caporusso S, Vieira-Neto OM, Figueiredo JFC, et al. Colonização por bactérias em cateter temporário de duplo lúmen para hemodiálise. J Bras Nefro 2003; 25 (Supl 1): 6 HD ENF 15.

22. Reis EMK, Pace AE. Otimização dos cuidados de enfermagem com o cateter de duplo lúmen e 0 impacto nos óbitos de nefropatas em hemodiálise. J Bras Nefro 2003; 25 (Supl 1): 8 HD ENF 21.

23. Jean G, Charra B, Chazot C, Vanel T, Terrat JC, Hurot JM, Laurent G. Risk factor analysis for long-term tunneled dialysis catheter-related bacteremias. Nephron 2002; 91: 399-405.

24. Sande FMV, Hermans MMH, Leunissen KML, Kooman JP. Noncardiac consequences of hypertension in hemodialysis patients. Sem Dialysis 2004; 17(4): 304-6. 